\title{
Otostegia persica biomass as a new biosorbent for the removal of lead from aqueous solutions
}

\author{
S. A. Alavi $\cdot$ H. Zilouei $\cdot$ A. Asadinezhad
}

Received: 10 December 2013/Revised: 4 October 2014/ Accepted: 27 October 2014/Published online: 7 November 2014

(C) Islamic Azad University (IAU) 2014

\begin{abstract}
Biosorption characteristics of $\mathrm{Pb}$ (II) ions from aqueous solution were studied using some residues of solvent-extracted Otostegia persica known as goldar residue biomass. The effects of contact time (0-120 min), the initial $\mathrm{pH} 3-8$, biomass dosage $(0.53-2.6 \mathrm{~g} / \mathrm{L})$ and the initial lead concentration $(5-25 \mathrm{mg} / \mathrm{L})$ on biosorption were investigated. The maximum adsorption capacity of $17.3 \mathrm{mg} / \mathrm{g}$ at $\mathrm{pH} 5.5$, the initial lead concentration of $25 \mathrm{mg} / \mathrm{L}$ and goldar residue biomass dosage of $1.06 \mathrm{~g} / \mathrm{L}$ were obtained. The results of equilibrium adsorption were studied through different isotherm models of Langmuir, Freundlich, Temkin, Halsey, Scachard and Dubinin-Radushkevich. Different kinetic models including pseudo-firstorder, pseudo-second-order and intraparticle diffusion were applied. The pseudo-second order described the adsorption kinetics data properly. Thermodynamic investigation at temperatures ranging from 25 to $45^{\circ} \mathrm{C}$ showed a reduction in both the possibility of adsorption and randomness at the solid-solution interface of goldar residue. Fourier transforms infrared analysis confirmed the presence of several functional groups on the surface of the goldar residue biomass during lead adsorption. $O$. persica residue biomass showed good properties to use as a new biosorbent for removal of low concentrations of lead ions from water.
\end{abstract}

Keywords Biosorption - Otostegia persica - Lead ions · Adsorption kinetics · Adsorption isotherm

S. A. Alavi · H. Zilouei $(\bowtie) \cdot$ A. Asadinezhad

Department of Chemical Engineering, Isfahan University of

Technology, 84156-83111 Isfahan, Iran

e-mail: hzilouei@cc.iut.ac.ir

\section{Introduction}

Nowadays, heavy metals such as lead, cadmium, nickel, mercury, zinc and copper are quite risky to the aquatic ecosystem as well as the human health. Rapid growth in industrial process and chemical manufacturing has given rise to the generation of large amounts of aqueous effluents containing significant quantities of various heavy metals (Chojnacka 2010; Bable and Kumiawan 2003). Pb is the most common metal contaminant in wastewater which is discharged by industrial processing methods such as electroplating, smelting, alloying, pigmenting, plastic manufacturing, mining, metallurgy and refining (Farooq et al. 2010). However, standards of lead in drinking water and foods have been declined during the last years by European Commission (EU) and US Food and Drug Administration (FDA).

Physicochemical methods such as precipitation, chemical oxidation or reduction, reverse osmosis, cementation and ion exchange processes have been employed for heavy metal elimination from industrial wastewater stream (Patrón-Prado et al. 2010; Ahn et al. 2009; Ali and Gupta 2006; Ali et al. 2012). These techniques are expensive from an economic viewpoint and have drawbacks such as incomplete metal removal, high energy requirements, generation of toxic sludge and other disposable waste products (Aksu 2001; Ali 2010, 2012). Recently, considerable attention has been given to the use of environmentally friendly materials for the elimination of heavy metals from diluted large volume streams. The use of biomass for removing heavy metals has been extensively practiced over the last decade, representing itself as an alternative to the present technologies.

Different types of biomass have been investigated for the biosorption of $\mathrm{Pb}$ (II) ions from aqueous solution. A 
variety of microorganisms have been found to have an innate capability to take off heavy metals. Recent biosorption experiments have been carried out using by-products or the waste materials from large-scale industrial operations such as the waste from cork production (Mesas et al. 2011), grape fruit (Bayo 2012), crop milling waste (Saeed et al. 2005), peat, the waste of tea leaves, sugar beet pulp, rice straw (Hlihor and Gavrilescu 2009; Bakir et al. 2010), sawdust (Costodes et al. 2003) and the waste from olive oil (Blazquez et al. 2010). These techniques have shown to be promising when compared to conventional treatment methods due to its low cost, high efficiency, easy regeneration of biosorbents and the possibility of metal recovery (Devaprasath et al. 2007).

Otostegia persica, known as goldar, is an endemic plant that can be found in its natural habitat in Kerman Province, Iran. Recent investigations on the aqueous extract of the plant have shown that it is antispasmodic, antihistaminic and antiarthritis (Ebrahimpoor et al. 2009). The residues of plant, after extractions, are not usable and therefore are discarded as waste. In this article, the residue of $O$. persica was used as a low-cost biosorbent. The aim of this study was to examine the ability of goldar residue to remove lead ions from a low initial concentration aqueous solution. This was followed by investigating the suitable isotherm along with the kinetic models. All the researches throughout this study were carried out from September 2012 to September 2013 in the Laboratory of Biotechnology, Isfahan University of Technology, Iran.

\section{Materials and methods}

\section{Biosorbent preparation}

The $O$. persica, provided from Kerman Desert, was finely powdered and extracted with methanol. After the removal of the solvent under the reduced pressure, the residue was re-extracted using hexane and chloroform (Yassa et al. 2005). The residue of extraction was collected and washed with distilled water to remove the residual and the extractor. It was finally dried at $60{ }^{\circ} \mathrm{C}$. Then the residue was milled and sieved to assume a size within $600-850 \mu \mathrm{m}$.

Lead solutions preparation

The standard stock solution of $\mathrm{Pb}^{2+}$ was prepared by dissolving an appropriate amount of $\mathrm{Pb}\left(\mathrm{NO}_{3}\right)_{2}$ in distilled water. The $\mathrm{pH}$ of the metal solution was adjusted to a desired value with $0.1 \mathrm{M} \mathrm{NaOH}$ and $0.1 \mathrm{M} \mathrm{HCl}$ using $\mathrm{pH}$ meter (Metrohm, 620, Switzerland). All the chemicals $\left(\mathrm{Pb}\left(\mathrm{NO}_{3}\right)_{2}, \mathrm{NaOH}\right.$ and $\left.\mathrm{HCl}\right)$ were purchased from Merck Company.
Batch biosorption experiments

Batch experiments included the analysis of the effect of the initial lead concentration, temperature, $\mathrm{pH}$, and biosorbent dosage on lead biosorption by goldar residue. These experiments were performed in $75 \mathrm{~mL}$ of $\mathrm{Pb}^{2+}$ solution for $120 \mathrm{~min}$ at room temperature $\left(25^{\circ} \mathrm{C}\right)$ on a rotary shaker (Labcon, FSIM-SPO16) at $140 \mathrm{rpm}$. The duration was long enough to reach the equilibrium state between the aqueous lead and the biosorbent. The optimum conditions of the adsorption were determined by experiments and maintained within various reaction time durations (0-120 min), biomass dosages $(0.53-2.6 \mathrm{~g} / \mathrm{L})$, initial lead concentrations (5-25 mg/L) and initial pHs (3-8). Each experiment was conducted at least twice. At the end of the experiments, a sample of $10 \mathrm{ml}$ was taken and centrifuged at $6,000 \mathrm{rpm}$ for $15 \mathrm{~min}$. The metal uptake was calculated as:

$Q=\frac{V\left(C_{0}-C_{\mathrm{eq}}\right)}{M}$

where $Q$ is the lead uptake $(\mathrm{mg} / \mathrm{g}), C_{0}$ and $C_{\text {eq }}$ are the initial and final lead concentrations in solution $(\mathrm{mg} / \mathrm{L}), V$ is the volume (L) and $M$ is the amount of biosorbent based on dry weight $(\mathrm{g})$.

\section{Biosorption isotherms}

The isotherm of adsorption was investigated by batch tests. Experiments were carried out in $100-\mathrm{mL}$ conical flasks containing $75 \mathrm{~mL}$ of the lead solution with the initial concentration range of $5-25 \mathrm{mg} / \mathrm{L}$ and the initial $\mathrm{pH}$ of 5.5 . A known amount of adsorbents (0.08 g) was added to each flask. The mixture was shaken in a rotary shaker at $140 \mathrm{rpm}$, keeping temperature constant $\left(25 \pm 2{ }^{\circ} \mathrm{C}\right)$. After $40 \mathrm{~min}$, the samples were centrifuged and analyzed quantitatively. Then, the most commonly adsorption isotherms were applied and investigated via the Langmuir, Freundlich, Scatchard, Halsey, Temkin and Doubinin-Radushkevich (D-R) models (Malkoc and Nuhoglu 2007; Asia and Oladoja 2008).

\section{Kinetics of adsorption}

Batch tests were performed to determine the kinetic adsorption properties of goldar residue for $\mathrm{Pb}$ ions. Experiments of adsorption kinetics were carried out in $100-\mathrm{mL}$ conical flasks containing $75 \mathrm{~mL}$ of the lead solutions by using $1.06 \mathrm{~g} / \mathrm{L}$ of biosorbents at the initial $\mathrm{pH}$ of 5.5. The flasks were agitated on a rotary shaker at $140 \mathrm{rpm}$ under a constant temperature $\left(25 \pm 2^{\circ} \mathrm{C}\right)$. Two bottles were removed at each predetermined time interval, and the samples were taken, centrifuged and analyzed. The results were studied and investigated using pseudo-first-order, 
pseudo-second-order and intraparticle diffusion kinetic models (Mata et al. 2008).

\section{Thermodynamic study}

The experiments related to thermodynamic parameters were performed by varying temperature from 25 to $45{ }^{\circ} \mathrm{C}$ using $1.06 \mathrm{~g} / \mathrm{L}$ of biosorbents added to $75 \mathrm{~mL}$ of lead solutions in $100-\mathrm{mL}$ conical flasks. After 40-min agitation, the samples were centrifuged and analyzed. Various thermodynamic parameters such as Gibbs free energy changes $\left(\Delta G^{\circ}\right)$, enthalpy changes $\left(\Delta H^{\circ}\right)$ and entropy changes $\left(\Delta S^{\circ}\right)$ were determined to study the adsorption process.

Fourier transforms infrared spectra study

Fourier transforms infrared (FTIR) spectra within the range of $600-4,000 \mathrm{~cm}^{-1}$ were recorded on a Bruker spectrometer. Biosorption experiment was performed with the initial lead concentration of $20 \mathrm{mg} / \mathrm{L}$, the initial $\mathrm{pH}$ of 5.5 and $1.06 \mathrm{~g} / \mathrm{L}$ of goldar residue. After $40 \mathrm{~min}$, the sample was centrifuged and washed with distilled water to remove the loosely bound ions or impurities. The adsorbent, before and after lead sorption, was dried at room temperature for $24 \mathrm{~h}$ and used for analysis. The samples were pulverized and pressed for the preparation of pellets. The background spectrum was automatically subtracted from that of sample.

\section{Results and discussion}

The effect of contact time on adsorption capacity

The effect of contact time on the biosorption of $\mathrm{Pb}$ (II) onto goldar residue biomass is shown in Fig. 1. The experimental data showed a rapid increase in the initial lead adsorption up to $40 \mathrm{~min}$. After this, the biosorption rate became slower, and finally, no further significant biosorption was noted beyond $2 \mathrm{~h}$. This could be attributed to a large number of vacant binding sites available for biosorption during the initial stage, which carried out via physical adsorption or ion exchange on the surface of goldar residues. After prolonging the contact time, the occupation of the remaining vacant sites was difficult as a result of the repulsive forces between $\mathrm{Pb}^{2+}$ ions in solid and liquid phases (Ozcan et al. 2009). The slower adsorption mentioned above may involve other mechanisms such as complexation, micro-precipitation and binding site saturation (Mohan et al. 2002). The very fast biosorption of goldar residue biomass makes this material appropriate for continuous water treatment systems. Baysal et al. used Candida albicans for removing $\mathrm{Pb}$ ions from aqueous solution, where adsorption was achieved almost

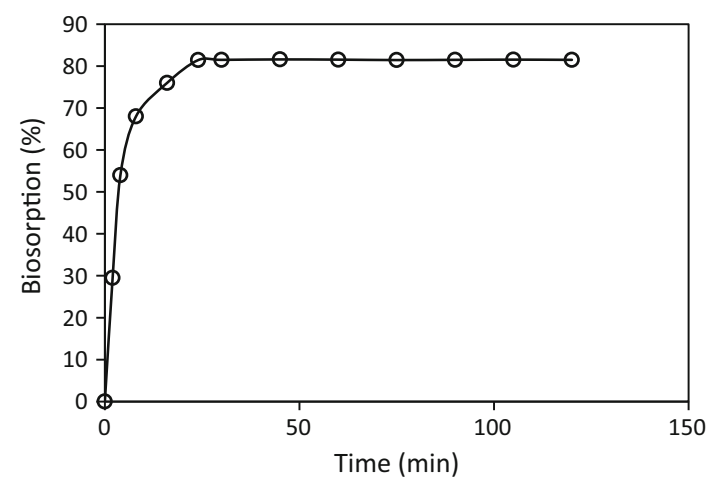

Fig. 1 Influence of interaction time on $\mathrm{Pb}$ (II) ions biosorption by goldar residue $\left(\mathrm{pH} 5.5, T=25 \pm 2{ }^{\circ} \mathrm{C}\right.$, the initial $\mathrm{Pb}$ concentration $=20 \mathrm{mg} / \mathrm{L}$, biomass dosage $=1.066 \mathrm{~g} / \mathrm{L}$ )

within 30 min (Baysal et al. 2009). Modified Symphoricarpus albus biomass was used for the treatment of lead solution, and the biosorption equilibrium was reached after 20 min (Tunali Akar et al. 2012).

The effect of the initial $\mathrm{pH}$

The effect of $\mathrm{pH}$ on metal biosorption has been studied by many researchers. The results have indicated that the $\mathrm{pH}$ values of solution can significantly influence biosorption. Different metal ions may have different $\mathrm{pH}$ optima, possibly due to the different solution chemistry of the species. The effect of the initial $\mathrm{pH}$ on the equilibrium uptake of lead ions has been investigated for $\mathrm{pH}$ values from 3 to 8 (Fig. 2). The sorption capacity of lead can be signifi-

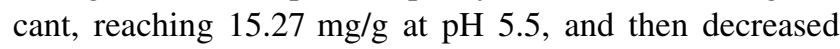
upon increasing the $\mathrm{pH}$ of solution. The low metal biosorption at $\mathrm{pH}$ below 3 could be expounded by the protonating active sites, resulting in a competition between $\mathrm{H}^{+}$and $\mathrm{Pb}^{2+}$ to take up the binding sites. On raising $\mathrm{pH}$, carboxyl groups were dissociated, leading to the attraction between negative charges and the metal ions, which, in turn, increased the adsorption onto the surface (Aksu 2001). Generally, metal biosorption involves complex mechanisms of ion exchange, chelating, adsorption by physical forces, microprecipitation, heavy metal hydroxide condensation and ion entrapment in the cell structural network of the biosorbent. It is well accepted that a combination of several mechanisms, each functioning independently, contributes to the overall metal uptake. The ATR-FTIR spectroscopic analysis showed that the moss biomass had a variety of functional groups, such as carboxyl, carbonyl (ketone), hydroxyl and amine. These groups were involved in almost all potential binding mechanisms. Moreover, depending on the $\mathrm{pH}$ value of the aqueous solution, these functional groups participate in metal ion bindings. 


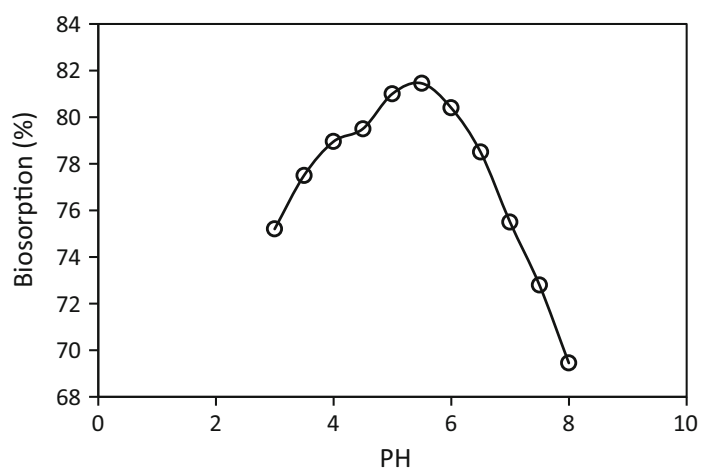

Fig. 2 Effect of the initial $\mathrm{pH}$ of the solution on the biosorption of $\mathrm{Pb}$ (II) by goldar residue $\left(T=25 \pm 2{ }^{\circ} \mathrm{C}\right.$, the initial $\mathrm{Pb}$ concentration $=20 \mathrm{mg} / \mathrm{L}$, biomass dosage $=1.066 \mathrm{~g} / \mathrm{L}$ )

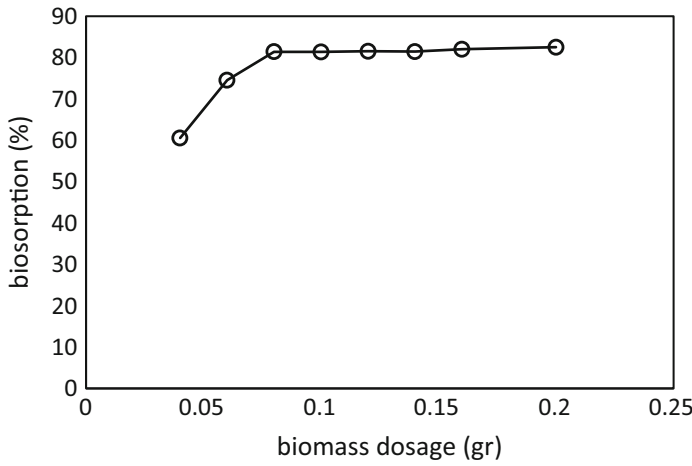

Fig. 3 Effect of goldar residue dosage on $\mathrm{Pb}$ (II) biosorption (pH 5.5, $T=25 \pm 2{ }^{\circ} \mathrm{C}$, the initial $\mathrm{Pb}$ concentration $=20 \mathrm{mg} / \mathrm{L}$ )

The effect of biomass dosage

The results from biosorption of lead studies using different biomass dosages in the range of $0.53-2.66 \mathrm{~g} / \mathrm{L}$ are illustrated in Fig. 3. The increase in adsorption upon increasing the adsorbent dosage can be attributed to the availability of a larger surface area and a higher number of sorption sites. At the low biomass dosage, it is known that the biosorbent surface becomes saturated with the metal ions, while the residual metal ion concentration in the solution is high (Romero-Gozalez et al. 2005). With an increase in biomass dosage, the lead ion removal is intensified. For the biomass dosage of $1.06 \mathrm{~g} / \mathrm{L}$, the incremental lead ion removal became very low as the surface metal ion concentration and the aqueous metal ion concentration reached the equilibrium state. For the higher adsorbent dosage, the removal efficiency of lead ions onto goldar residue was leveled off. Therefore, the optimum biomass dosage was chosen to be $1.06 \mathrm{~g} / \mathrm{L}$ for further experiments. Schiewer and Balaria investigated the biosorption of lead onto citrus peels biomass for the sorbent dosages of 0.1 up to $1.0 \mathrm{~g} / \mathrm{L}$; the

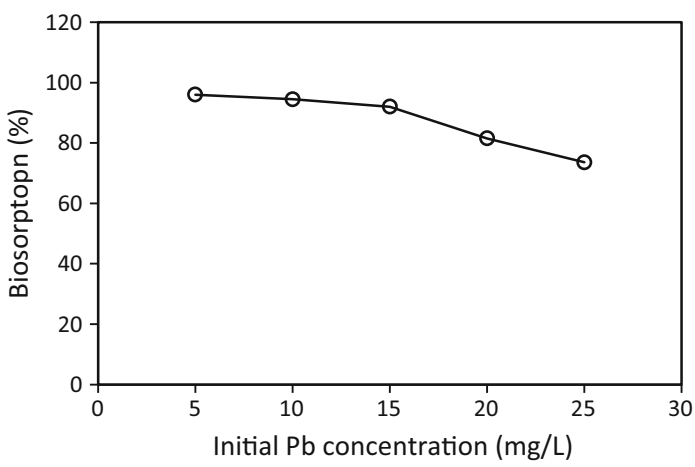

Fig. 4 Effect of the initial $\mathrm{Pb}(\mathrm{II})$ ions concentration on its biosorption by goldar residue ( $\mathrm{pH} 5.5, \quad T=25 \pm 2{ }^{\circ} \mathrm{C}$, biomass dosage $=1.066 \mathrm{~g} / \mathrm{L}$ )

results of this study showed the maximum sorption at $1.0 \mathrm{~g} / \mathrm{L}$ of biomass dosage (Schiewer and Balaria 2009). In another study by Qaiser et al., the Ficus religiosa leaves were used for the biosorption of lead ions and $10 \mathrm{~g} / \mathrm{L}$ biomass dosage (in the range of $1.0-50 \mathrm{~g} / \mathrm{L}$ ) was obtained for the maximum removal of lead (Qaiser et al. 2007). Elsewhere, waste biosorbent from Cucumis melo biomass was exploited for biosorption within the dosage of $0.6-4.0 \mathrm{~g} / \mathrm{L}$, where the biosorbent dosage of $1.8 \mathrm{~g} / \mathrm{L}$ yielded the optimum biosorption (Tunali Akar et al. 2012).

The effect of the initial lead concentration

The effect of lead concentration in the range of 5-25 mg/L on the sorption by goldar residue is shown in Fig. 4 at $\mathrm{pH}$ of 5.5 for $40 \mathrm{~min}$ equilibrium time. The biosorption was decreased from 96 to $73.6 \%$ upon increasing the initial lead concentration, while $q_{\mathrm{e}}$ was increased from 4.5 to $17.25 \mathrm{mg} / \mathrm{g}$. This behavior could be attributed to the fact that all binding sites on the biomass surface are vacant, resulting in the high initial metal biosorption. The initial $\mathrm{Pb}$ (II) concentration in the solution, which provided an important driving force to overcome the mass transfer resistance of the metal ions between the aqueous and solid phases, together with the high contact and collision between $\mathrm{Pb}$ ions and the biosorbent caused an increase in the biosorption of $\mathrm{Pb}$ ions (Donmez and Aksu 2002). When the adsorbent to metal ratio was low, $\mathrm{Pb}$ (II) ions in the solution were not only adsorbed onto the surface of the adsorbent, but also they penetrated into the intracellular part as a result of the concentration gradient of $\mathrm{Pb}$ ions (Ozcan et al. 2009).

The effect of temperature

The influence of temperature was explored within $25-45{ }^{\circ} \mathrm{C}$ under the optimum $\mathrm{pH}$ value of 5.5 and the biomass dosage of $1.06 \mathrm{~g} / \mathrm{L}$. The biosorption percentage 
was decreased from 81.5 to $76.5 \%$ as temperature was increased from 25 to $45^{\circ} \mathrm{C}$. This indicated the exothermic nature of lead biosorption using goldar residue biomass. A decrease in the biosorption of $\mathrm{Pb}$ (II) ions by raising the temperature could be due to deactivation of the biosorbent surface or destruction of some active sites on the biosorbent surface due to bond ruptures (Meena et al. 2005). In addition, the decrease in biosorption efficiency could be attributed to an increase in the tendency to desorb the metal ions from the interface to the solution (Ozer and Ozer 2003). In another study on the biosorption of $\mathrm{Pb}$ (II) ions using marine green algae (U. lactuca $s p$.), it was found that with increasing the temperature form 10 to $40{ }^{\circ} \mathrm{C}$, the rate of metal uptake was decreased from 55.9 to $43.5 \mathrm{mg} / \mathrm{L}$ (Bulgariu and Bulgariu 2012).

Modeling of adsorption isotherms

Isotherm studies provide information on the capacity of sorbent as the most important parameter for an adsorption process. The experiments were carried out with different initial concentrations of lead solution in the range of $5-25 \mathrm{mg} / \mathrm{L}$. Characterization of a sorption system is often done using several isotherm models encompassing Langmuir, Freundlich, Temkin, Halsey, Scatchard and DubininRadushkevich (D-R) isotherm equations (Asia and Oladoja 2008; Dawodu et al. 2012). All of these isotherm models were applied. The respective data are presented in Table 1. The Langmuir model assumes the monolayer adsorption of metal ions on a homogenous surface without any interaction between the adsorbed ions. The Langmuir isotherm can be described according to the following formula:

$q_{\mathrm{e}}=\frac{q_{\mathrm{m}} b C_{\mathrm{e}}}{1+b C_{\mathrm{e}}}$

where $q_{\mathrm{e}}$ is the equilibrium metal ion concentration on the sorbent $(\mathrm{mg} / \mathrm{g}), C_{\mathrm{e}}$ is the equilibrium metal ion concentration in the solution $(\mathrm{mg} / \mathrm{L}), q_{\mathrm{m}}$ is the monolayer biosorption capacity of the sorbent $(\mathrm{mg} / \mathrm{g})$, and $b$ is the Langmuir biosorption constant $(\mathrm{L} / \mathrm{mg})$, which is related to the free energy of biosorption. Langmuir isotherm for the adsorption of $\mathrm{Pb}$ ions on goldar residue is shown in Fig. 5a, where the maximum sorption capacity $\left(q_{\mathrm{m}}\right)$ equals $18.86 \mathrm{mg} / \mathrm{g}$. The Freundlich model assumes a heterogeneous adsorption surface and active sites with different energy levels. The Freundlich model is expressed as:

$q_{\mathrm{e}}=K_{\mathrm{f}} C_{\mathrm{e}}^{1 / \mathrm{n}}$

where $K_{\mathrm{f}}$ is a constant related to the biosorption capacity and $1 / \mathrm{n}$ is an empirical parameter connected with the biosorption magnitude, which varies with the heterogeneity of the material. Freundlich isotherm for the adsorption of
Table 1 Isotherm constants of lead adsorption by goldar residue biomass

\begin{tabular}{llll}
\hline Isotherm model & Constants & & $R^{2}$ \\
\hline Langmuir & $q_{\mathrm{m}}=18.86$ & $b=1.6$ & 0.998 \\
Freundlich & $K_{\mathrm{f}}=9.76$ & $n=2.739$ & 0.905 \\
D-R model & $q_{\mathrm{m}}=15.54$ & $\beta \times 10^{8}=6.525$ & 0.971 \\
Scatchard & $q_{\mathrm{m}}=18.76$ & $K_{\mathrm{b}}=1.606$ & 0.984 \\
Halsey & $K=38.46$ & $n=1.92$ & 0.695 \\
Temkin & $A_{\mathrm{T}}=21.067$ & $b_{\mathrm{T}}=691.47$ & 0.975 \\
\hline
\end{tabular}
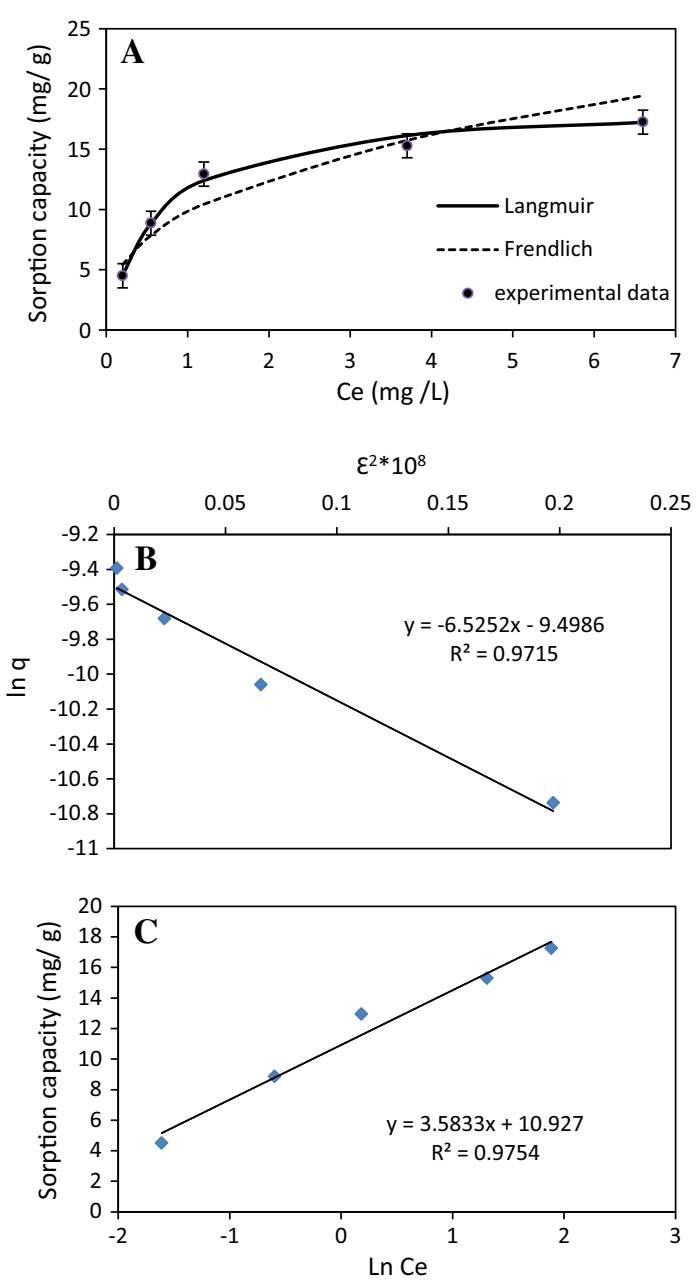

Fig. 5 Experimental and calculated adsorption isotherms of $\mathrm{Pb}(\mathrm{II})$ on goldar residue a Langmuir and Freundlich, b Temkin isotherm and c D-R biosorption isotherm ( $\mathrm{pH} 5.5, T=25 \pm 2{ }^{\circ} \mathrm{C}$, biomass dosage $=1.066 \mathrm{~g} / \mathrm{L}$ )

$\mathrm{Pb}$ ions on goldar residue is shown in Fig. 5a. From nonlinear Freundlich isotherm plots, $K_{\mathrm{f}}$ and $n$ values were found to be $9.76 \mathrm{mg} / \mathrm{g}$ and 2.739 , respectively. The Dubinin-Radushkevich isotherm model was used to predict the characteristics of adsorption processes in terms of physical or chemical aspects. The linearized D-R isothermequationcanbewrittenasfollows: 
$q_{\mathrm{e}}=q_{\mathrm{m}} \exp \left(-\beta \varepsilon^{2}\right)$

where $q_{\mathrm{m}}$ is the maximum sorption capacity $(\mathrm{mg} / \mathrm{g}), \beta$ is the activity coefficient related to mean sorption energy $\left(\mathrm{mol}^{2} / \mathrm{j}^{2}\right)$, and $\varepsilon$ is the Polanyi potential according to:

$\varepsilon=R T \ln \left(1+1 / C_{\mathrm{e}}\right)$

The D-R isotherm model fitted well the equilibrium data, where $R^{2}$ value was around 0.971 (Fig. 5b). The $q_{\mathrm{m}}$ value was found from intercept to be $15.54 \mathrm{mg} / \mathrm{g}$. The sorption energy can also be calculated using the following equation:

$E=\frac{1}{\sqrt{2 \beta}}$

If $E$ value lies between 8 and $16 \mathrm{~kJ} / \mathrm{mol}$, the biosorption process takes place chemically and when $E<8 \mathrm{~kJ} / \mathrm{mol}$, the biosorption process proceeds physically (Lodeiro et al. 2006). The value of $E=2.768 \mathrm{~kJ} / \mathrm{mol}$ shows that the physical adsorption is predominant in the biosorption process.

The Scatchard plot analysis, also called independent site-oriented model, was applied to study the affinity of binding sites and analyze the result of the adsorption isotherm. The Scatchard plot equation is given as:

$q_{\mathrm{e}} / c_{\mathrm{e}}=q_{\mathrm{m}} K_{\mathrm{b}}-q_{\mathrm{e}} K_{\mathrm{b}}$

where $q_{\mathrm{m}}(\mathrm{mg} / \mathrm{g})$ and $K_{\mathrm{b}}(\mathrm{L} / \mathrm{mg})$ are the Scatchard adsorption isotherm constants. If the plot of $q_{\mathrm{e}} / C_{\mathrm{e}}$ versus $q_{\mathrm{e}}$ gives a straight line, then the adsorbent consists of only one type of binding site (homogenous surface) (Anirudhan and Suchithra 2012).

The Halsey adsorption isotherm is suitable for multilayer adsorption, and by fitting the experimental data to this equation, it confirms the heteroporous nature of the adsorbent. The Scatchard plot is linear with a negative slope related to the interaction between the $\mathrm{Pb}$ ions and the binding sites that obeys the Langmuir model. The isotherm equation is (Basar 2006):

$\ln q_{\mathrm{e}}=\frac{1}{n} \ln k-\frac{1}{n} \ln c_{\mathrm{e}}$

where $k$ and $n$ are isotherm parameters. The Halsey isotherm model fitted the equilibrium data, and the $R^{2}$ value was 0.695 . These results showed that this model was not suitable for experimental data.

The Temkin isotherm, whose formula follows, takes into account the interactions between goldar residue and $\mathrm{Pb}$ ions. It is based on the assumption that the free energy of sorption is a function of the surface coverage (Deng and Ting 2005):

$q_{\mathrm{e}}=\frac{R T}{b_{\mathrm{T}}} \ln \left(A_{\mathrm{T}} C_{\mathrm{e}}\right)$ where $A_{\mathrm{T}}$ is equilibrium binding constant corresponding to the maximum binding energy $(\mathrm{L} / \mathrm{mg}), \mathrm{b}_{\mathrm{T}}$ is the Temkin isotherm constant, $T$ is the temperature $(K)$, and $R$ is the ideal gas constant $(8.314 \mathrm{~J} / \mathrm{mol} / \mathrm{K})$. Temkin isotherm for the adsorption of $\mathrm{Pb}$ ions is shown in Fig. 5c. The value of $R^{2}$ for this model was estimated to be 0.975 . The whole calculated isotherm parameters are presented in Table 1 .

Kinetic modeling of lead adsorption

The prediction of adsorption rate is useful for properly designing the batch adsorption systems. The experimental data were fitted with pseudo-first-order, pseudo-secondorder and intraparticle models to study the adsorption kinetics of lead onto goldar residue. Adsorption rate of $\mathrm{Pb}$ (II) ions was rapid at the first adsorption process. It was, however, slowed down after $40 \mathrm{~min}$. The adsorption rate in pseudo-first-order model depends on the concentration of only one reactant. The rate constant $k_{1}$ for the adsorption of $\mathrm{Pb}(\mathrm{II})$ has been studied by Lagergren rate equation ( $\mathrm{Yu}$ et al. 2003) with the initial $\mathrm{Pb}$ (II) concentration of $20 \mathrm{mg} / \mathrm{L}$ :

$\log \left(q_{\mathrm{e}}-q_{\mathrm{t}}\right)=\log q_{\mathrm{e}}-\frac{k_{1}}{2.303} t$

where $q_{\mathrm{e}}$ and $q_{\mathrm{t}}(\mathrm{mg} / \mathrm{g})$ are the amounts of $\mathrm{Pb}$ (II) ions adsorbed at equilibrium and instant $t(\mathrm{~min})$, respectively; $k_{1}$ represents the rate constant of the equation $\left(\mathrm{min}^{-1}\right)$. The adsorption rate constant $\mathrm{k}_{1}$ is presented in Table 2. The plots of $\log \left(q_{\mathrm{e}}-q_{\mathrm{t}}\right)$ versus $t$ for the pseudo-first-order model are almost linear, indicating the validity of Lagergren rate equation of the first-order kinetics.

The pseudo-second-order equation, based on adsorption equilibrium capacity, assumes that the rate at which the adsorption sites are filled is proportional to the square of the number of unoccupied sites. It is expressed as (Parab et al. 2005):

$\frac{t}{q_{\mathrm{t}}}=\frac{1}{k_{2} q_{\mathrm{e}}^{2}}+\frac{t}{q_{\mathrm{e}}}$

where $K_{2}$ is the rate constant of sorption ( $\left.\mathrm{g} / \mathrm{mg} \min \right)$. The rate constant $k_{2}$ and $R^{2}$ values are presented in Table 2 . The experimental value of $q_{\mathrm{e}}$ was not matched well with the calculated value for the pseudo-first-order kinetics. Therefore, the pseudo-second-order model is more useful for describing the biosorption kinetic process precisely. This means that the physical adsorption is fast, while the chemical adsorption is slow. So, chemisorption mechanism, like valence forces and ion exchange on the surface, could be the rate controlling step, not the intraparticle diffusion.

In order to evaluate the contribution of the diffusion of lead ions within the goldar residue in the whole biosorption 
Table 2 Kinetic parameters of lead adsorption by goldar residue biomass

\begin{tabular}{|c|c|c|c|c|c|c|c|c|}
\hline \multicolumn{3}{|l|}{ Pseudo-first-order } & \multicolumn{3}{|l|}{ Pseudo-second-order } & \multicolumn{3}{|c|}{ Intraparticle diffusion } \\
\hline$k_{1} \times 10^{1}(1 / \mathrm{min})$ & $q_{1}(\mathrm{mg} / \mathrm{g})$ & $R^{2}$ & $k_{2} \times 10^{2}(\mathrm{~g} / \mathrm{mg} \mathrm{min})$ & $q_{2}(\mathrm{mg} / \mathrm{g})$ & $R^{2}$ & $k_{\text {id }}\left(\mathrm{mg} / \mathrm{g} \min ^{0.5}\right)$ & $C$ & $R^{2}$ \\
\hline 1.32 & 10.196 & 0.983 & 1.74 & 17.24 & 0.99 & 2.378 & 4.289 & 0.934 \\
\hline
\end{tabular}

process, the intraparticle diffusion model was applied to the experimental data. They are mathematically written as (Ma et al. 2007):

$q_{\mathrm{t}}=k_{\mathrm{id}} t^{0.5}+c$

where $k_{\text {id }}$ is the intraparticle diffusion rate constant and $C$ is the adsorption constant. The rate constant $k_{\mathrm{id}}$ and the $R^{2}$ values are given in Table 2 and Fig. 6. The mechanism of this model is delineated based on the following steps: bulk diffusion into the solid-liquid interface, intraparticle diffusion including the penetration of metal ions into the interior solid surface from available pores of the adsorbent and finally, metal adsorption at the active sites of the adsorbent (Chen et al. 2010).

Thermodynamic study of lead adsorption

In order to investigate the thermodynamics of lead sorption by goldar residue, the experiments were performed at different temperatures with an initial lead concentration of $20 \mathrm{mg} / \mathrm{L}$. The thermodynamic parameters, including standard enthalpy changes $\left(\Delta H^{\circ}\right)$, standard entropy changes $\left(\Delta S^{\circ}\right)$ and standard Gibbs free energy changes $\left(\Delta G^{\circ}\right.$ ), were estimated from the following equations (Ho 2007):

$\Delta G^{0}=-R T \ln K_{\mathrm{D}}$

$\ln K_{\mathrm{D}}=\frac{\Delta S^{0}}{R}-\frac{\Delta H^{0}}{R T}$

where $R$ is the universal gas constant $(8.314 \mathrm{~J} / \mathrm{mol} \mathrm{K}), T$ is temperature $(K)$, and $\mathrm{K}_{\mathrm{D}}\left(q_{\mathrm{e}} / C_{\mathrm{e}}\right)$ is the distribution coefficient. Gibbs free energy change $\left(\Delta G^{\circ}\right)$ was found to be $-1.956,-1.516,-1.247,-0.986$ and $-0.664 \mathrm{~kJ} / \mathrm{mol}$ at $298,303,308,313$ and $318 \mathrm{~K}$, respectively. Biosorption is usually a spontaneous process, and negative values of $\Delta G^{\circ}$ at all temperatures result from this characteristic. The feasibility of biosorption is decreased upon raising the temperature. The calculated value for $\Delta H^{\circ}$ was $-20.508 \mathrm{~kJ} / \mathrm{mol}$. At the temperature range of $20-45{ }^{\circ} \mathrm{C}$, $\Delta H^{\circ}$ was negative, indicating the exothermic nature of the biosorption processes. Furthermore, the negative value of $\Delta S^{\circ}(-62.447 \mathrm{~J} / \mathrm{mol} \mathrm{K})$ was suggestive of a decrease in the randomness at the solid-solution interface during biosorption (Table 3).

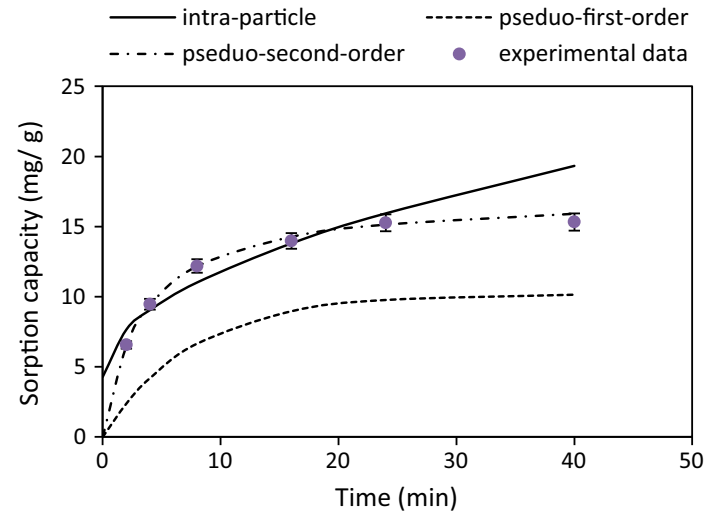

Fig. 6 Kinetic model plots for the adsorption of $\mathrm{Pb}(\mathrm{II})$ ions by goldar residue $\left(\mathrm{pH} 5.5, T=25 \pm 2{ }^{\circ} \mathrm{C}\right.$, the initial $\mathrm{Pb}$ concentration $=20 \mathrm{mg} / \mathrm{L}$, biomass dosage $=1.066 \mathrm{~g} / \mathrm{L}$ )

ATR-FTIR analysis of lead ions-goldar residue interaction

ATR-FTIR spectroscopy was used to detect vibrational frequency changes in the adsorbent. The results are illustrated in Fig. 7. They show the FTIR spectra of goldar residue biomass before and after lead adsorption. These results give information regarding the available functional groups on the surface of goldar residue biomass which can be used for possible interactions between these functional groups and $\mathrm{Pb}$ (II) ions (Javanbakht et al. 2014). There are some changes in goldar residue samples before and after $\mathrm{Pb}$ adsorption. The strong and broad band at $3,393 \mathrm{~cm}^{-1}$ might be related to the overlap between amine $(\mathrm{N}-\mathrm{H})$ and hydroxyl $(\mathrm{O}-\mathrm{H})$ stretching vibrations. The bands peaks at 2,920 and $2,851 \mathrm{~cm}^{-1}$ could be due to the bounded $(-\mathrm{CH})$ group. However, the strong peaks at $1,700,1,606$ and $1,512 \mathrm{~cm}^{-1}$ could be related to asymmetric and symmetric stretching vibration of $\mathrm{C}=\mathrm{O}$ groups, and the peaks at 1,512 and $1,419 \mathrm{~cm}^{-1}$ might be assigned to the stretching of $\mathrm{N}-\mathrm{H}$ group on the biomass surface (Gao et al. 2011). The bands observed at 1,371 and $1,318 \mathrm{~cm}^{-1}$ were due to $-\mathrm{N}=\mathrm{O}$ stretching vibrations for goldar residue. The bands at 1,251 and $1,079 \mathrm{~cm}^{-1}$ were ascribed to the stretching of $\mathrm{C}-\mathrm{O}$ groups on the biomass surface, and some peaks in the fingerprint region could be related to the phosphate groups. It could be 
Table 3 Thermodynamic constants of lead adsorption by goldar residue biomass

\begin{tabular}{lllllll}
\hline$\Delta \mathrm{H}^{0}$ & $\Delta \mathrm{S}^{0}$ & \multicolumn{2}{l}{$\Delta \mathrm{G}^{0}(\mathrm{~kJ} / \mathrm{mol})$} & & & $R^{2}$ \\
\cline { 2 - 7 }$(\mathrm{kJ} / \mathrm{mol})$ & $(\mathrm{J} / \mathrm{mol} \mathrm{K})$ & $298 \mathrm{~K}$ & $303 \mathrm{~K}$ & $308 \mathrm{~K}$ & $313 \mathrm{~K}$ & $318 \mathrm{~K}$ \\
\hline-20.508 & -62.447 & -1.956 & -1.516 & -1.247 & -0.986 & -0.664 \\
\hline
\end{tabular}

Fig. 7 ATR-FTIR spectra of goldar residue before $(a)$ and after $(b)$ the biosorption process $\left(\mathrm{pH} 5.5, T=25 \pm 2{ }^{\circ} \mathrm{C}\right.$, the initial $\mathrm{Pb}$ concentration $=20 \mathrm{mg} / \mathrm{L}$, biomass dosage $=1.066 \mathrm{~g} / \mathrm{L}$ )

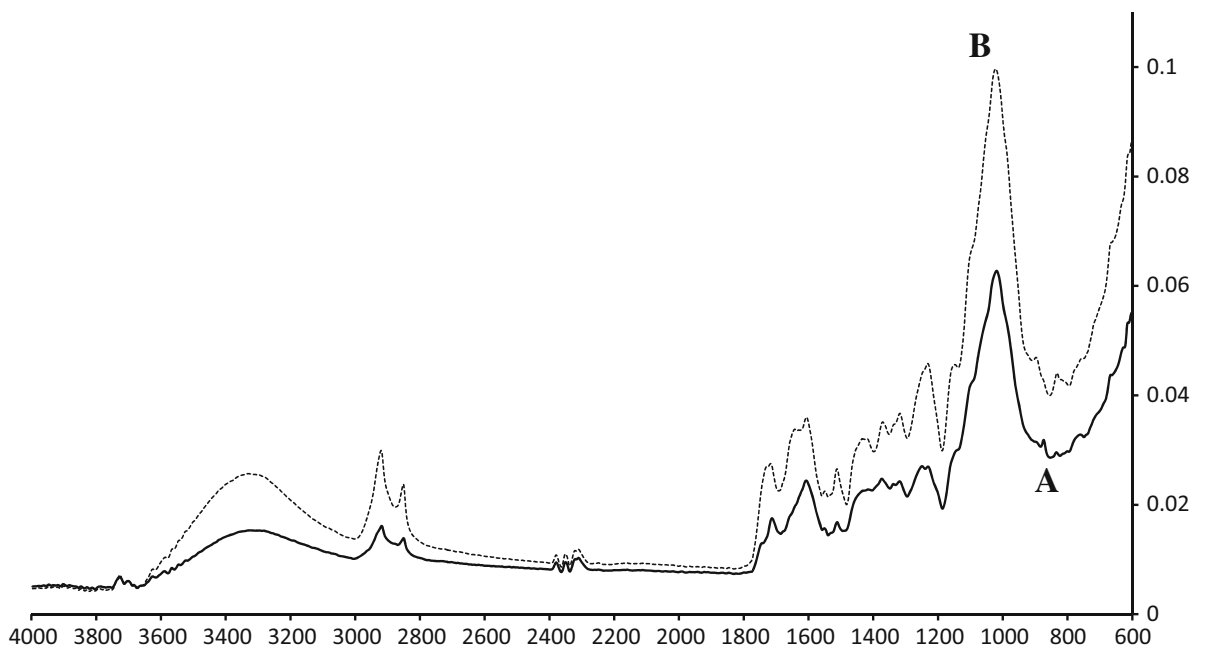

Table 4 Comparison of adsorption capacities of different adsorbents for removal of lead ions

\begin{tabular}{|c|c|c|c|c|c|}
\hline Biosorbent & $\begin{array}{l}\text { Concentration } \\
\text { range } \\
\text { of } \mathrm{Pb}(\mathrm{mg} / \mathrm{L})\end{array}$ & $\begin{array}{l}\text { Contact } \\
\text { time } \\
(\min )\end{array}$ & $\begin{array}{l}\text { Sorbent } \\
\text { dosage } \\
(\mathrm{g} / \mathrm{L})\end{array}$ & $\begin{array}{l}\text { Removal } \\
\text { capacity } \\
(\mathrm{mg} / \mathrm{g})\end{array}$ & References \\
\hline $\begin{array}{l}\text { Algal biomass Sargassum } \\
\text { glaucescens }\end{array}$ & $0-100$ & 120 & 2 & 45.8 & $\begin{array}{l}\text { Montazer-Rahmati et al. } \\
\text { (2011) }\end{array}$ \\
\hline $\begin{array}{l}\text { Algal biomass Nizimuddinia } \\
\text { zanardini }\end{array}$ & $0-100$ & 120 & 2 & 50.4 & $\begin{array}{l}\text { Montezer-Rahmati et al. } \\
\text { (2011) }\end{array}$ \\
\hline Raw agave bagasse & $0-100$ & - & $1-2$ & 35.6 & $\begin{array}{l}\text { Velazquez-Jimenez et al. } \\
\text { (2013) }\end{array}$ \\
\hline Treated agave bagasse & $0-100$ & - & $1-2$ & 54.3 & $\begin{array}{l}\text { Velazquez-Jimenez et al. } \\
\text { (2013) }\end{array}$ \\
\hline Raw corncob & - & - & - & 16.2 & Tan et al. (2010) \\
\hline Modified corncob & - & - & - & 43.4 & Tan et al. (2010) \\
\hline Coconut tree sawdust & 10-200 & 90 & 4 & 25.0 & Putra et al. (2014) \\
\hline Egg shell & 10-200 & 90 & 4 & 90.9 & Putra et al. (2014) \\
\hline Sugarcane bagasse & $10-200$ & 90 & 4 & 21.3 & Putra et al. (2014) \\
\hline Otostegia persica waste biomass & $2-25$ & 40 & 1.1 & 17.3 & This study \\
\hline Pseudomonas aeruginosa in beads & 73.4 & 15 & 200 & 0.7 & Lin and Lai (2006) \\
\hline Ethanol-treated baker's yeast & $5-25$ & $15-60$ & 1 & 17.5 & Goksungur et al. (2005) \\
\hline Live Aspergillus niger & 10 & 300 & 1.3 & 2.3 & Kapoor et al. (1999) \\
\hline $\mathrm{NaOH}$-pretreated $A$. niger & 10 & 300 & 1.3 & 7.2 & Kapoor et al. (1999) \\
\hline
\end{tabular}

observed that the bands at $3,324,1,713,1,249$ and $874 \mathrm{~cm}^{-1}$ were shifted to $3,330,1,717,1,232$ and $833 \mathrm{~cm}^{-1}$, respectively, after loading $\mathrm{Pb}(\mathrm{II})$. The changes in the wave number of these bands after the loading of
$\mathrm{Pb}$ (II) indicated the involvement of the functional groups (C-O and $\mathrm{C}=\mathrm{O}$, amido, hydroxyl) in the biosorption of $\mathrm{Pb}$ (II) on the surface of goldar residue biomass (Murphy et al. 2007; Lodeiro et al. 2006). 
A comparison of adsorption capacities of different biosorbents, which have been used by researchers for removal of lead ions from aqueous solutions, is presented in Table 4. Together with biosorbent capacity, availability of the biosorbent and its preparation cost are factors affecting the practical use of biosorbents (Kapoor et al. 1999). Contact time to reach equal conditions and biomass dosage are also other parameters which have been very different. Initial concentration of $\mathrm{Pb}$ (II) ions is an important parameters, in which, it can affect the residual concentration of metal ions in the aqueous solution. As it is seen in Table 4, different researchers have applied different initial concentration, while the aim of this work was adsorption of low concentrations of lead ions.

\section{Conclusion}

The residue of solvent-extracted $O$. persica or goldar residue biomass was used for the first time in the adsorption of lead from water. A maximum adsorption capacity of $17.3 \mathrm{mg} / \mathrm{g}$ was obtained at the $\mathrm{pH}$ of 5.5 , the initial lead concentration of $25 \mathrm{mg} / \mathrm{L}$ and goldar residue biomass dosage of $1.06 \mathrm{~g} / \mathrm{L}$. Kinetics of adsorption was properly described by the pseudo-second-order model. FTIR analysis confirmed the presence and responsibility of several functional groups on the surface of goldar residue biomass during lead adsorption. These results showed that goldar residue biomass could be the high potential biosorbent of heavy metals.

Acknowledgments This research was financed by Iran National Science Foundation (Project Number 87046/16).

\section{References}

Ahn CK, Park D, Woo SH, Park JM (2009) Removal of cationic heavy metal from aqueous solution by activated carbon impregnated with anionic surfactants. J Hazard Mater 164:1130-1136

Akar ST, Arslan D, Alp T (2012) Ammonium pyrrolidine dithiocarbamate anchored Symphoricarpus albus biomass for lead(II) removal: batch and column biosorption study. J Hazard Mater 227:107-117

Aksu Z (2001) Equilibrium and kinetic modeling of cadmium(II) biosorption by $C$. vulgaris in a batch system: effect of temperature. Sep Purif Technol 21:285-294

Ali I (2010) The quest for active carbon adsorbent substitutes: inexpensive adsorbents for toxic metal ions removal from wastewater. Sep Purif Rev 39:95-171

Ali I (2012) New generation adsorbents for water treatment. Chem Rev 112:5073-5091

Ali I, Gupta VK (2006) Advances in water treatment by adsorption technology. Nature London 1:2661-2667

Ali I, Asim M, Khan TA (2012) Low cost adsorbents for the removal of organic pollutants from wastewater. J Environ Manage 113:170-183
Anirudhan TS, Suchithra PS (2012) Equilibrium, kinetic and thermodynamic modeling for the adsorption of heavy metals onto chemically modified hydrotalcite. Indian J Chem Technol $17: 242-259$

Asia I, Oladoja N (2008) Studies on the sorption of basic dye by rubber (Hevea brasiliensis) seed shell. Turkish J Eng Environ Sci 32:143-152

Bable S, Kumiawan TA (2003) Low-cost adsorbents for heavy metals uptake from contaminated water-a review. J Hazard Mater 97:219-243

Bakir A, Mcloughlin P, Fitzgerald E (2010) Regeneration and reuse of a seaweed based biosorbent in single and multi-metal systems. Clean Soil Air Water 38:257-262

Basar CA (2006) Applicability of the various adsorption models of three dyes adsorption onto activated carbon prepared waste Apricot. J Hazard Mater 135:232-241

Bayo J (2012) Kinetic studies for Cd(II) biosorption from treated urban effluents by native grapefruit biomass (Citus paradise L.): the competitive effect of $\mathrm{Pb}(\mathrm{II}), \mathrm{Cu}$ (II) and $\mathrm{Ni}(\mathrm{II})$. Chem Eng J 191:278-287

Baysal Z, Ercan C, Bulut Y, Alkan H, Dogru M (2009) Equilibrium and thermodynamic studies on biosorption of $\mathrm{Pb}$ (II) onto Candida albicans biomass. J Hazard Mater 161:62-67

Blazquez G, Calero M, Hernainz F, Tenorio G, Martin-lara M (2010) Equilibrium biosorption of lead(II) from aqueous solution by solid waste from olive-oil production. Chem Eng J 160:615-622

Bulgariu D, Bulgariu L (2012) Equilibrium and kinetics studies of heavy metal ions biosorption on green algae waste biomass. Bioresour Technol 103:489-493

Chen S, Yue Q, Gao B, Xu X (2010) Equilibrium and kinetic adsorption study of the adsorptive removal of $\mathrm{Cr}(\mathrm{VI})$ using modified wheat residue. J Colloid Interf Sci 349:256-264

Chojnacka K (2010) Biosorption and bioaccumulation-the prospects for practical application. Environ Int 36:299-307

Costodes V, Fauduet H, Porte C, Delacroix A (2003) Removal of $\mathrm{Cd}$ (II) and $\mathrm{Pb}$ (II) ions from aqueous solution by adsorption onto sawdust of Pinus sylvestris. J Hazard Mater 105:121-142

Dawodu FA, Akpomie GK, Abuh MA (2012) Equilibrium isotherm studies on the batch sorption of Copper(II) ions from aqueous solution onto Nsu clay. Int J Sci Eng Res 3:1-7

Deng S, Ting YP (2005) Fungal biomass with grafted poly (acrylic acid) for enhancement of $\mathrm{Cu}(\mathrm{II})$ and $\mathrm{Cd}(\mathrm{II})$ biosorption. Langmuir 21:5940-5948

Devaprasath PM, Solomon JS, Thomas BV (2007) Removal of Cr(VI) from aqueous solution using natural plant material. J Appl Sci Environ Sanit 2:77-83

Donmez G, Aksu Z (2002) Remove of chromium(VI) from saline waste water by Dunaliella species. Process Biochem 38:751-762

Ebrahimpoor MR, Khaksar Z, Noorafshan A (2009) Antidiabetic effect of Otostegia persica oral extract on streptozotocindiabetic rats. Res J Biol Sci 4(12):1227-1229

Farooq U, Kozinski JA, Khan MA, Athar M (2010) Biosorption of heavy metal ions using wheat based biosorbents-a review of the recent literature. Bioresour Technol 101:5043-5053

Gao JF, Zhang Q, Wang JH, Wu XL, Wang SY, Peng YZ (2011) Contributions of functional groups and extracellular polymeric substances on the biosorption of dyes by aerobic granules. Bioresour Technol 102:805-813

Goksungur Y, Uren S, Guvenc U (2005) Biosorption of cadmium and lead ions by ethanol treated waste baker's yeast biomass. Bioresour Technol 96:103-109

Hlihor R, Gavrilescu M (2009) Removal of some environmentally relevant heavy metal using low-cost natural sorbent. Environ Technol 8:353-372

Ho YS (2007) Removal of copper ions from aqueous solution by tree fern. Water Res 37:2323-2330 
Javanbakht V, Alavi SA, Zilouei H (2014) Mechanisms of heavy metal removal using microorganisms as biosorbent. Water Sci Technol 69:1775-1787

Kapoor A, Viraraghavan T, Cullimore DR (1999) Removal of heavy metals using the fungus Aspergillus niger. Bioresour Technol 70:95-104

Lin CC, Lai YT (2006) Adsorption and recovery of lead(II) from aqueous solutions by immobilised Pseudomonas Aeruginosa PU21 beads. J Hazard Mater A137:99-105

Lodeiro P, Barriada JL, Herrero R, Sastrede Vicente ME (2006) The marine macroalga Cystoseira baccata as biosorbent for cadmium(II) and lead(II) removal: kinetic and equilibrium studies. Environ Pollut 142:264-273

Ma W, Ya FQ, Han M, Wang R (2007) Characteristics of equilibrium, kinetics studies for adsorption of fluoride on magnetic-chitosan particle. J Hazard Mater 143:296-302

Malkoc E, Nuhoglu Y (2007) Determination of kinetic and equilibrium parameters of the batch adsorption of $\mathrm{Cr}(\mathrm{VI})$ onto waste acorn of Quercus ithaburensis. Chem Eng Process 46:1020-1029

Mata Y, Blazquez M, Ballester A, Gonzalez F, Munoz J (2008) Characterization of the biosorption of cadmium, lead and copper with the brown alga Fucus vesiculosus. J Hazard Mater 158:316-323

Meena AK, Mishra GK, Rai PK, Rajagopal C, Nagar PN (2005) Removal of heavy metal ions from aqueous solutions using carbon aerogel as an adsorbent. J Hazard Mater 122:161-170

Mesas M, Navarrete E, Carrillo F, Palet C (2011) Bioseparation of $\mathrm{Pb}$ (II) and $\mathrm{Cd}(\mathrm{II})$ from aqueous solution using Cork waste biomass: modeling and optimization of the parameters of the biosorption step. Chem Eng J 174:9-17

Mohan SV, Rao NC, Prasad KK, Karthikeyan J (2002) Treatment of simulated reactive yellow 22 (Azo) dye effluents using Spirogyra species. Waste Manage 22:575-582

Montazer-Rahmati MM, Rabbani P, Abdolali A, Keshtkar AR (2011) Kinetics and equilibrium studies on biosorption of cadmium, lead, and nickel ions from aqueous solutions by intact and chemically modified brown algae. J Hazard Mater 185:401-407

Murphy V, Hughes H, Mcloughlin P (2007) Cu(II) binding by dried biomass of red, green and brown macroalage. Water Res 41:731-740

Ozcan AS, Tunali S, Akar T, Ozcan A (2009) Biosorption of lead(II) ions onto waste biomass of phaseolus vulgaris L.: estimation of the equilibrium, kinetic and thermodynamic parameters. Desalination 244:188-198
Ozer A, Ozer D (2003) Comparative study of the biosorption of $\mathrm{Pb}(\mathrm{II}), \mathrm{Ni}(\mathrm{II})$ and $\mathrm{Cr}(\mathrm{VI})$ ions onto $S$. cerevisiae: determination of biosorption heats. J Hazard Mater 100:219-229

Parab H, Joshi S, Shenoy N, Verma R, Lali A, Sudersanan M (2005) Uranium removal from aqueous solution by coir pith: equilibrium and kinetic studies. Bioresour Technol 96:1241-1248

Patrón-Prado M, Acosta-Vargas B, Serviere-Zaragoza E, MéndezRodríguez L (2010) Copper and cadmium biosorption by dried seaweed Sargassum sinicola in saline wastewater. Water Air Soil Pollut 210:197-202

Putra WP, Kamari A, Mohd Yusoff SN, Ishak CF, Mohamed A, Hashim N, Isa IM (2014) Biosorption of $\mathrm{Cu}$ (II), $\mathrm{Pb}$ (II) and $\mathrm{Zn}$ (II) ions from aqueous solutions using selected waste materials: adsorption and characterization studies. J Encapsul Adsorpt Sci 4:25-35

Qaiser S, Saleemi AR, Ahmad MM (2007) Heavy metal uptake by agro based waste materials. Electron J Biotechnol 10(3). doi:10. 2225/vol10-issue3-fulltext-12

Romero-Gozalez J, Peraita JR, Rodruguez E, Ramirez SL, Gardeatorresdey JL (2005) Determination of thermodynamic parameters of $\mathrm{Cr}(\mathrm{VI})$ adsorption from aqueous solution onto Agave lechuguilla biomass. J Chem Thermodyn 37:343-347

Saeed A, Iqbal M, Akhtar M (2005) Removal and recovery of lead(II) from single and multimetal $(\mathrm{Cd}, \mathrm{Cu}, \mathrm{Ni}, \mathrm{Zn})$ solutions by crop milling waste (black gram husk). J Hazard Mater 117:65-73

Schiewer S, Balaria A (2009) Biosorption of $\mathrm{Pb}^{2+}$ by original and protonated citrus peels: equilibrium, kinetics and mechanism. Chem Eng J 146:211-219

Tan G, Yuan H, Liu Y, Xiao D (2010) Removal of lead from aqueous solution with native and chemically modified corncobs. J Hazard Mater 174:740-754

Tunali Akar S, Arslan S, Tugba A, Arslan D, Akar T (2012) Biosorption potential of the waste biomaterial obtained from Cucumis melo for the removal of $\mathrm{Pb}^{2+}$ ions from aqueous media: equilibrium, kinetic, thermodynamic and mechanism analysis. Chem Eng J 185:82-90

Velazquez-Jimenez LH, Pavlick A, Rangel-Mendez JR (2013) Chemical Characterization of raw and treated agave bagasse and its potential as adsorbent of metal cations from water. Ind Crop Prod 43:200-206

Yassa N, Sharififar F, Shafiee A (2005) Otostegia persica as a source of natural antioxidants. Pharm Biol 43:33-38

Yu LJ, Shukla SS, Dorris KL, Shukla A, Margrave JL (2003) Adsorption of chromium from aqueous solution by maple sawdust. J Hazard Mater 100:53-63 